\title{
Kronik Prostatit/Kronik Pelvik Ağrı Sendromunda Etyoloji ve Tanı
}

\author{
Fikret Erdemir ${ }^{1}$
}

${ }^{1}$ Gaziosmanpaşa Üniversitesi, Tıp Fakültesi, Üroloji Anabilim Dalı, Tokat

\section{Giriș}

$\mathrm{P}$ rostatit kelime anlamı olarak prostat bezinin inflamasyonu olsa da geleneksel olarak alt üriner sistem yakınmaları, inflamasyon, prostat kökenli ağrı ve etyopatogenezi tam olarak anlaşılamayan klinik tabloyu ifade etmek için kullanılmaktadır (1). 19. yüzyılın başında bu durumun doğrudan ata binme ve cinsel ilişki ile ilişkili olduğu düşünülmüştür (2). Son dönemlerde yapılan geniş çalışmalar sonrası hastalığın aslında sanılandan daha kapsamlı ve daha geniş semptom kümesine sahip olduğu anlaşılmaktadır. Buna göre kronik pelvik ağrı sendromunda (tip 3 kronik prostatit) (KPAS) nedenler, uygulanan tedaviler ve etyopatogenez hala tartışmalı olup; geleneksel yöntemlerle olguların ancak \%5-10'unda etken patojenin gösterilebilmesi, klinik olarak prostatit tanısı konulan hastaların bir kısmının histolojik incelemelerinde prostatit tanısının gösterilememesi ya da histolojik olarak prostatit tanısı konulan hastaların bir kısmında hiçbir klinik yakınmanın olmaması henüz tam olarak açıklanamamıştır (1). Tüm yaş gruplarında \%8-14 oranında saptanan prostatitler 50 yaş altında en sık, 50 yaş üzerinde ise benign prostat hiperplazisi $(\mathrm{BPH})$ ve prostat kanseri ile birlikte üçüncü sıklıkta tanı konulan üriner sistem hastalığıdır. Yapılan popülasyon çalışmalarında erişkin erkeklerin \%2-30'unda hayatlarının herhangi bir döneminde geçirilmiş prostatit ile uyumlu şikayetler bulunduğu saptanmıştır. Hastaların sosyal yaşamlarını ciddi olarak etkileyen prostatitlerin yaşam kalitelerine olan olumsuz etkileri stabil olmayan anjina pektoris, akut myokard infarktüsü, aktif Crohn hastalığı ve diyabetes mellitus ile benzer olarak saptanmıştır. Prostatit insidansı coğrafi bölgelere göre de (\%2.2-12) farklılık göstermektedir.
Otopsi serilerinde bile bilinen prostat hastalığ 1 olmayanlarda \%44 oranında prostatit saptandığı bildirilmektedir (1-3). Literatürde çeşitli dönemlerde farklı sınıflamalar olmakla beraber en son ulusal sağlık enstitüsünün yaptığı sınıflama esas alınmaktadir (4).

$\mathrm{Bu}$ siniflamaya göre akut bakteriyel prostatitler \%1-2, kronik bakteriyel prostatitler \%4-5 oranlarında görülürken tüm prostatitlerin \%90-95'ini oluşturan KPAS, tedavi ve etiyopatogenezindeki zorluklar ve belirsizlikler nedeniyle zor bir grubu oluşturmaktadır. Tüm prostatit türlerinde olduğu gibi KPAS gelişiminde de pek çok etyolojik ajan suçlanmıştır. Ancak, özetle söylemek gerekirse kabul edilen görüş KPAS gelişiminde tek bir faktörün değil, birden fazla etkenin rol oynadığıdır. Özellikle son 10 yılda KPAS konusunda gerek moleküler, gerek doku düzeyinde gerekse de klinik ve deneysel anlamda çok sayıda çalışmanın yapıldığı görülmektedir. Çeşitli ülkelerde yapılan çalışmalarda KPAS'taki prevalansın \%2.7-16 arasında değişebildiği anlaşılmaktadır (5-13).

KPAS görülme sıklığının yaş ile birlikte arttı̆̆ $35-50$ yaş aralığında görülme riskinin 35 yaş öncesine göre yaklaşık 2-3 kat fazla olduğu bildirilmiştir (14). Hastalığın tanısının konulması için yakınmaların her ne kadar bazı yayınlarda 3 ay kadar olması gerektiği belirtilse de 6 aylık yakınmaların olması ve yılda bir ya da birkaç kez ataklarla seyretmesi önemlidir. Tanıdan 87 ay öncesine kadar semptomlar sözkonusu olabilmektedir (2). Bu patolojide var olan ağrı ya da hassasiyet yaşam kalitesini bozan en önemli yakınmadır. Ağrı sıklıkla perine, skrotum ve perineal bölgede yer almaktadır. Ağrının kaynağı ya da lokalizasyonunun hastalığın patogenezi ya da hastalığın şiddeti ile ilişkili olmadığını belirtmek gerekmektedir (14). Toplam 1563 olgunun ince-

Tablo 1: Ulusal Sağlık Enstitüsü sınıflaması (4).

\begin{tabular}{ll}
\hline Tip I & Prostatın akut enfeksiyonu \\
Tip II & Prostatın kronik bakteriyel enfeksiyonu \\
Tip III & $\begin{array}{l}\text { Kronik pelvik ağrı sendromu (KPAS): Standart yöntemlerle prostat içinde üropatojen bir bakteri olmadan } \\
\text { kronik ürogenital ağrı olması }\end{array}$ \\
Tip IIIA (İnflamatuvar) & $\begin{array}{l}\text { Prostat masajı sonrası idrar sedimentinde, semende ya da prostat sekresyonunda belirgin lökosit (>10) } \\
\text { bulunmasıdır. }\end{array}$ \\
Tip IIIB (non-inflamatuvar) & $\begin{array}{l}\text { Prostat masajı sonrası prostat sekresyonu, sediment ya da semende önemsiz sayıda lökosit (<10)bulunmasıdır. } \\
\text { Tip IV }\end{array}$ \\
& $\begin{array}{l}\text { Herhangi bir yakınması olmayanlarda infertilite ya da prostat kanseri araştırması için yapılan incelemelerde } \\
\text { semende ya da prostatik histolojik örneklerde lökosit veya bakteri bulunmasıdır. }\end{array}$ \\
\hline
\end{tabular}


lendiği bir çalışmada perineal ağrı \%63, testiküler ağrı \%58, pubik ağrı \%42, penis ağrısı \%32, ejakülasyon sırasında ağrı $\% 45$ ve işeme sırasında ağrı ise \%43 olarak bildirilmiştir (15). KPAS'ta sık idrara çıkma, idrar yaparken zorlanma, kesik kesik idrar yapma, idrar yaptıktan sonra rahatlayamama, damlama gibi depolama ve boşaltım şeklinde kendini gösteren alt üriner sistem yakınmaları, psikojenik sorunlar, erektil disfonksiyon ya da ejakülasyon bozuklukları ve rektal yakınmalar sözkonusu olabilir. Bu yakınmalar içerisinde ağrılı ejakülasyon ya da ejakülasyon sonrası ağrı olması tipiktir. Kronik prostatitli olguların \%21.5 ile \%77'sinde cinsel işlev bozuklukları görüldüğü bildirilmiştir $(1,16)$. Yaşları 20 ile 59 yıl arasında değişen kronik prostatitli hastaların değerlendirildiği bir çalışmada cinsel işlev bozukluğu oranı \%49 olarak bildirilirken 146 hastanın değerlendirildiği bir başka çalışmada bu oran \%92 olarak bildirilmektedir $(17,18)$. Kronik prostatitin neden olduğu hiperemi ve ödemin ereksiyon merkezini sürekli olarak uyardığı ve etkisini bozabildiği bildirilmektedir. Sonuçta ihtiyaç anında ereksiyonun zor olabileceği belirtilmektedir (19). Kronik prostatitli hastalarda ejakülasyon bozukluğunun açıklanmasında, inflamasyonun duyusal feedback mekanizmasını bozarak ejakulatuvar refleksi artırması ve orgazm öncesi kontrolün kalkması ileri sürülmektedir. Kronik prostatitli hastalarda ejakulasyon bozukluğu oranı \%20-77 arasında değişmektedir (20-23). Boşaltım semptomlarında, işeme ile ilişkisiz ya da işeme sonrası peniste künt ağrı olması ve rahatlayamama tipiktir. Hastalarda sık sık gayta yapma ihtiyacı ve yaptıktan sonra rahatlayamama sözkonusu olabilmektedir.

Amerika Birleşik Devletleri'nde her yıl yaklaşık 2 milyon kadar hastanın prostatit benzeri yakınmalarla hekimlere başvurduğu ve her yıl bu sayıya 267000 hastanın eklendiği bilinmektedir (24). Bu hali ile hastalar ayrıntılı sorgulanmad1ğında ya da hasta tarafından ayrıntılı olarak anlatılmadığında bir semptom kümesine yönelerek genel tablonun görülmesinden ziyade sadece BPH ya da üretral darlık, sadece üretrit, sadece rektal tümör, sadece cinsel işlev bozukluğu ya da nörolojik bir patoloji düşünülebilir. Yer yer bu olgularda yan ağrısı ve gastrointestinal semptomlar da tabloya eşlik ettiğinden farklı patolojiler üzerine yoğunlaşılabilir. Bir başka ifadeyle; ürolojik açıdan sadece birkaç semptomun öne çıkması inkontinans ile uğraşan bir üroloji uzmanına nörojenik mesane ya da işeme disfonksiyonunu, tümör ile uğraşan bir uzmana rektal ya da üriner tümörü, genel üroloji uzmanına ya da endoüroloji ile uğraşan bir uzmana mesane boynu yüksekliği ya da BPH'yı ya da ağırlıklı olarak androloji ile ilgilenen bir üroloji uzmanına cinsel işlev boukluğunu düşündürebilir. Aslında bütün bu yakınmalar tek bir hastal1ğın farklı yansımaları olarak da; ifade edilebilir. Bu anlamda araştırmacılar tarafından kar tanesi fenomeni (snowflake) bu durumu belirtmek için ortaya konulmuştur $(25,26)$. Buna göre kar tanelerinin oldukça farklı çeşitte olsa da aslında aynı temel yapıdan oluşması gibi KPAS'ın da farklı yansımaları olsa da tek bir patolojinin yansıması olduğu düşünülmektedir. Kar tanesi hipotezi temelinde ilk olarak Shoskes tarafindan fenotipik özellikler kullanılarak UPOINTs sistem geliştirilmiştir (Tablo 2). Bu sistemin geliştirilmesindeki amaç, hastalığ1 daha iyi değerlendirmek ve uygun tedavilerin ortaya konulmasıdır. Bu sistemin uygulanabilirliği ve yararı çalışmalarda gösterilmiştir (27-29). Bundan başka UPOINT sisteminin tedavi başarısını arttırmada önemli olduğu söylenebilir.
Tablo 1: UPOINTs sistemi
U- Üriner semptomlar
P - Psikososyal yakınmalar
O- Organ-spesifik yakınmalar
I - İnfeksiyon ilişkili yakınmalar
N- Nörolojik/sistemik yakınmalar
T - Kaslarda hassasiyuet ve pelvik taban yakınmaları
S - Cinsel işlev bozukluğu

Yukarıda da belirtildiği üzere KPAS olarak bilinen tip III kronik prostatit, gerek hastalar; gerekse hekimler için tanı ve tedavisinde yaşanılan sorunlar ve zorluklar nedeniyle nispeten sıkıntılı bir hastalık grubu olarak kabul edilmektedir. Buna göre, 1916 yılında yayınlanan bir makalede de araştırmacılar, makale sonunda "maalesef bu hastalıktan kurtulmanın ve tedavisinin çok zor olduğunu" belirterek umutsuz bir tablo çizmektedirler (30). Günümüzde de bu durumun büyük ölçüde benzer olduğunu söylemek yanlış olmaz.

KPAS tanısının konulması için kılavuzlar lokal patolojinin gösterilmemesini yani ekartasyonun önemli olduğunu belirtmektedirler. Buna göre uretra ya da mesane tümörü, prostat kanseri, uretral darlık, aktif üriner infeksiyon ve taş gibi patolojilerin yokluğunda ortaya çıkan klasik semptom kümesi KPAS olarak adlandırılmaktadır. Geleneksel olarak prostat sekresyonlarında üreme olmaması temel kriterlerden biridir. KPAS'ta her ne kadar prostat sekresyonlarında üreme olmaması temel koşul olsa da; yeni dönemde araştırmacılar bu yaklaşımın doğru olmadığını iddia etmektedirler. Buna göre, "geleneksel yöntemlerle bakılan klasik mikroorganizmaların ortaya konulamaması bu patolojide mikroorganizma olmadığı anlamına gelmemektedir" tezi ileri sürülmektedir. Bu tezi ileri süren araştırmacılar yaptıkları çalışmalarda normal florada da olmadığı belirtilen H. Pilori, C. Trachomatis ve T. Vaginalis başta olmak üzere pek çok mikroorganizmanın farklı yöntemlerle saptandığını belirtmektedirler (31-36). $\mathrm{Bu}$ araştırmacılar aynı zamanda son dönemde yaptıkları çalışmalarda KPAS' ta mikroorganzimalara ait 16S rRNA'nın \%65-88 oranlarında saptandığını bildirmişlerdir (37-39). Bundan başka prostatitli olgularda geçmiş hikayelerinde üriner sistem infeksiyonu öyküsü KPAS olmayanlara göre daha fazladır (36).

$\mathrm{Bu}$ çalışmalarda lokal defans sisteminin bozulmasının, radyolojik çalışmalarda ve belirli maddelerin işaretlenmesiyle elde edilen sonuçlara göre üretradan prostat içine olan kanalların gösterilmesi sonucu mikroorganizmaların buraya reflüsü, fimozis, korunmasız cinsel ilişki, transüretral cerrahi, geçirilmiş üretral girişim ya da katater uygulamalarının mikroorganizma yerleşmesinde etkili olabileceği belirtilmiştir. Bunun yanında, disfonksiyonel yüksek basınçlı işemenin etyopatogenezde önemli olabileceği görülmektedir. Yüksek basınçlı disfonksiyonel işemeye ikincil olarak intraprostatik duktal reflü oluşur ve sonuçta mikroorganizmalar, antijenler, lökosit, spermatozoa, ürat metabolitleri ve kreatininin eşlik ettiği inflamatuvar reaksiyon oluşarak, ağrı reseptörleri ile patogenez başlatılmış olur. İntraprostatik reflünün bir diğer etkisi prostatın savunma mekanizmasında bozulmaya neden ol $\neg$ masıdır. Prostatın sekretuvar mekanizmasının bo $\neg$ zulması sonucu prostat sıvısının fruktoz, sitrik asit, asit fosfataz, çinko, magnezyum ve kalsiyum dü $\neg$ zeylerinde azalma ve prostatı enfeksiyonlara karşı koruyucu rol oyna- 
yan $\mathrm{pH}$, laktatdehidrogenaz 5/laktatdehidrogenaz 1 oranı ve seruloplazmin gibi inflamatuvar proteinler ve $\mathrm{C} 3$ düzeyinde artış olmaktadır. Bununla birlikte, bu yapısal değişiklikาlerin sonucunda $\mathrm{m}$ inlamasyonun oluştuğu, yoksa inflamasyona bağlı olarak $\mathrm{m}$ bu değişikliklerin geliş̧tiği henüz açık değildir. Yine belli kan gruplarında mikroorganizmaların ya da spesifik bakteri suşlarının prostat afinitesinin olabileceği ileri sürülmüştür (40). Klinik çalışmalarda KPAS'lı olguların ürodinamik incelemelerinde mesane çııı obstrüksiyonu, detrusor aşırı aktivitesi, hiperestezi, detrusor sfinkter disinerjisi gibi suprasakral patolojilerde de görülebilecek bulgulara sahip oldukları bildirilmiştir $(41,42)$. Bir çalışmada detrusor sfinkter dissinerjisinin \%18.6 civarında görüldüğü bildirilmiştir (43). Yine nanobakterilerin prostatta taş oluşumuna yol açacağı, bunun da; KPAS etiyopatogenezinde rol alabileceği vurgulanmaktadır (44). Evans ve ark'larının ortalama yaşları 38.7 yıl olan 131 olguyu inceledikleri çalışmalarında transrektal ultrasonografi incelenmesinde \%16.2 oranında prostatik kalsifikasyon ve $\% 9.4$ oranında da prostat taşları saptanmıştır (44). Sonuçta ne olursa olsun mikroorganizma, idrar metabolitleri, yabancı protein ya da sperm gibi diğer etkenler mast hücreleri, endotoksinler, sitokin ve kemokinlerin aracılığı ile lökositleri de; inflamasyon alanına çekerek inflamatuar süreci başlatmaktadırlar. Oluşan inflamasyona sekonder olarak, periprostatik ya da prostatik reseptörler aracılığ ile spinal kanal ve santral sinir sistemine uyarıların taşındığı bildirilmektedir. Lokal olarak prostatta meydana gelen patoloji doku düzeyinde hassasiyet ve basınç oluşturmaktadır. Burada bahsedilen sitokinler ve kemokinler hücre sinyal molekülleridir ve gerek proinflamatuar, gerek inflamatuar gerekse de onarım sürecinde yer alan çok sayıda alt başlıkta incelenmektedir (45-50). Bu hücre sinyalleri aracılığı ile lökositler artmakta ve ekstraprostatik sekresyonda (EPS) saptanmaktadır. EPS'de lökosit varlığ 1 ve derecesi ile semptomların korele olmadığı pek çok çalışmada ortaya konulmuştur (51). KPAS'ta sıklıkla periferal zondan başlayarak periuretral alana ulaşan inflamasyon sonrası glanüler atrofi, stromal fibrozis sözkonusu olabilmektedir. Prostatta meydana gelen inflamasyona bağlı olarak COX-2 ve bunun neticesinde PGE2 artışı, mast hücre ve mast hücre ilişkili TRKA ve sonrasında NGF artışı, TRPV1 ve bununla ilişkili olarak SP, CGRP, PACAP artışları ağrı ile ilişkili mediatörlerdir (49-50). PGE2 dokuda hipoksi, ödem ve ATP fonksiyon bozukluğu yapmaktadır (49). Burada sözkonusu olan mast hücreleri oldukça önemli olup bu hücreler vücutta yer alan dokularda kan damarları, sinirler ve diş çevre ile ilişkide olan yüzeylerde yer alan ve dış madde girişine karşı savunma hattında ilk yer alan hücreler olarak bilinmektedir. Mast hücrelerinin olmaması ağrının olmadığı inflamasyon anlamına gelmektedir (36). Sitokinler içerisinde yer alan antiinflamatuar sitokin olan IL-10' un KPAS etiyolojisinde ve ağrıda yer aldığı bilinmektedir (52). Mast hücrelerinden salınan nerve growth factor (NGF) oldukça önemlidir. Oluşan inflamasyon doku hasarı ve NGF artışı ile seyretmektedir. Bu durum yeni sinir liflerinin oluşması ya da aktive olması anlamına gelmektedir. Bu ajanın ağrı seviyesiyle korele olduğu gösterilmiştir. NGF'nin ratlarda termal ve mekanik uyaranlar sonrası sensitiviteyi arttırdığı, hiperaljeziye neden olduğu ortaya konulmuştur. Aynı şekilde gönüllü insanlara enjekte edilmesinin de; ağrı ile ilişkili sensitiviteyi arttırdığı gösterilmiştir $(52,53)$. Sitokinler hem bulundukları bölgeye lökosit infiltrasyonu sağlamakla bir- likte salgıladıkları proteazlarla dokulardaki hümoral ve hücresel cevabı düzenlerler (54). A $\beta$ lifleri inhibitör, $A \delta-C$ lifleri stimülatör olarak bilinirken $\mathrm{KPAS}^{\prime}$ ta hepsinin stimülatör özellik kazandığ 1 sessiz myelinsiz $C$ fiberlerinin aktif hale gelerek SP, CGRP aracıllğı ile ağrı ve hassasiyet oluşturduğu bildirilmektedir $(55,56)$. KPAS olgularında hassasiyet sözkonusudur ve bu hassasiyet bioteziometri çalı̧̧maları ile özellikle perineal alanda ortaya konulmuştur (56). Bununla ilişkili olarak Korkmaz ve ark'larının KPAS tanısı olan 17 olguyu 17 kontrol grubu ile kıyasladıkları çalışmada sinir ileti hızının anlamlı olarak arttığı bu sonuçların santral sensitizasyonu desteklediğini belirtmişlerdir (56). KPAS olgularinda meydana gelen patolojinin reseptör düzeyinde alg1lanması bir süre sonra santral ve periferik sinir sisteminde bazı değişiklikler meydana getirmektedir. Buna göre yeni akson bağlantıları olabileceği gibi, beyinde iletişim ağının kontrol grubuna göre oldukça geniş olduğu bildirilmiştir. Öte yandan bu olgularda normal bireylerin normal uyaranlara gösterdiği standart hücresel nöronal tepkilerin aksine hiperaljezi olarak adlandırılan abartılı ağrı yanıtı oluşmakta ya da herhangi bir ağrılı uyaran olmadan ağrısız uyaranlara karşı da; prastotodini denilen durum oluşmaktadır. Santral sensitizasyon spinal seviyede cFos tarafından arttırılmaktadır. Bundan başka, inhibitör nöronların kaybının sözkonusu olabileceği aberan eksitatör sinaptik bağlantıların olabileceği belirtilmektedir. Bazı reseptörlerdeki nörotransmitterlerdeki fosforilasyon, sensitizasyonu değiştirerek aktivasyon eşik değerini düşürebilmektedir. İnflamasyona bağlı olarak ya da farklı nedenlerle kan spinal bariyerin bozulmasının spinal seviyedeki değişikliklerle ilgili olabileceği spinal seviyede mikroglia genişlemesinin bunun göstergesi olduğu kabul edilmektedir. CCL3, IL-1 $\beta$, Iba1 ve ERK1/2 gibi maddelerin artmasının nöron aktivasyon eşiğini düşürdügü, spinal seviyede P2X4R, BDNF artı̧ı ve PAR2, cFos, Ca artışı olmasının moleküler düzeyde KPAS ile ilişkiyi açıklayabilecek nörotransmitterler olduğu kabul edilmektedir $(57,58)$. Östradiol tarafından oluşturulan rat prostatit modelinde artan matriks metaloproteinazların (MMP-2 ve MMP-7'nin) lökosit infiltrasyonu, epitelyal atrofi ve doku hasarından sorumlu olabileceği bildirilmiştir (59). Spinal korddan biraz daha üst merkezlerin KPAS ile olan ilişkisi incelendiğinde kortikal, bazal ganglion ve talamik bölgelerde, anterior singulat girusta fonksiyonel MR incelemelerinde kontrol grubuna göre farklılıklar olduğu saptanmıştır $(59,60)$. Yine bu incelemelerde mikroyapısal ilişki ve bağlantıların kontrol grubundan farklı olduğu anlaşılmaktadır. Ayrıca, gri madde beyaz madde oranlarında değişiklik görüldüğü gabapentin verilmesine yanıt alınmamasının ki; bu ajan daha çok nörojenik ağrılarda kullanılmaktadır, nörolojik bir bozukluğu desteklediği belirtilmektedir. KPAS olgularının \%88'ine yakınında pelvik taban hassasiyeti söz konusu olabilmektedir. Pratikte bu olguların fizik muayenelerinde pelvik bölgede myofasial tetik noktaları olarak bilinen yerlerin olduğu anlaşılmaktadır. Bu olguların fizik muayenelerinde bant şeklinde noktaların olduğu fark edilmektedir $(61,62)$. Ancak, pelvik taban hassasiyeti olanların ağırlıklı bir kısmında EPS normal olarak tespit edilmektedir. Sözkonusu pelvik hassasiyetin EPS ile ilişkisiz olduğunu da belirtmemiz gerekmektedir. Bu olgularda pelvik taban kaslarında kontraksiyon ya da relaksasyon açısından sorun olduğu anlaşılmaktadır $(63,64)$. Öte yandan, yapılan çalışmalarda mesane tabanının kontrol grubuna göre daha hareketli olduğu anlaşılmıştır (65). Bu 
haliyle KPAS'ın aslında nöromusküler bir bozukluğun yansıması olduğu belirtilmektedir. Buna kanit olarak pelvik taban bozukluğu olan KPAS'lı hastalarda posterior insula değişiklikleri, bulbospongioz ve iskiokavernoz refleksin anormal oluşu ve anal sfinkter anomalisi olması ileri sürülmektedir. Bu bozukluktan hiperpolarizasyon ya da VAV proteinlerinin sorumlu olabileceği de belirtilmektedir (66).

Daha moleküler düzeye bakılacak olursak çinko ve sitratın enzimatik kataliz, sinyal redüksiyonu, lokal immün yanit, hücre proliferasyonu, farklılaşması ve apoptozis, nöron aktivasyonu ve çalışması, hücre proliferasyonu ve sağkalımında önemli olan survivin ekspresyonunu hipoksi indükleyen faktör-1 aracılığıyla indirekt etkilediği, antimikrobiyal ve antiinflamatuar süreçte yer aldığı bilinmektedir (67-69). Çinko yetersizliği ya da dengesizliğinin de lokal çevresel ortamı değiştirerek KPAS'a yol açabileceğine ait çalışmalar bulunmaktadır (68-70). Buradan hareketle çinko tedavisinin KPAS olgularında alternatif tedavi olabileceği belirtilmektedir.

Obezitenin tüm dünya için ciddi bir tehdit oluşturduğu hipertansiyon, kardiyovasküler sistem hastalıkları ve diabetes mellitusla bağlantılı olduğu hipertansiyon ve diabetes mellitusta ise sempatik sinir siteminin uyarıldığı porostat kapsülü ve mesane boynunda yer alan alfa adrenerjik aktivitenin artmasının KPAS'ta semptomların artmasina neden olabileceği ileri sürülmektedir $(71,72)$. Yine obezitenin kendisi inflamatuar bir süreç olup aynı inflamasyonun prostatta da kendini gösterdiği belirtilmektedir. Testosteronun nöroprotektif olduğu östrojenin ise inflamatuar süreçlerle ilişkili olduğu bilinmektedir. Kastrasyon yapılan ratların ağrılı uyaranlara karşı kastre edilmeyenlere göre daha fazla ağrı kesiciye ihtiyaç duydukları, dişi ratlara androjen verilmesiyle ise ağrı kesiciye olan ihtiyaçlarının azaldığı gösterilmiştir $(73,74)$.

Hem depresyon ve kaygının KPAS etiyolojisinde yer ald1ğı; hem de KPAS'ın kişilerin ruh sağlığını etkileyerek depresyon ve kaygıya yol açtığı oldukça iyi bilinmektedir (75-77). Bundan başka KPAS ve depresyonu olan olgularda depresyon tedavisinin KPAS'1 olmayanlara göre daha zor olduğu ortaya konulmuştur (75-77). Buna göre psikojenik alt yapının ağrıyı başlattığı, devam ettirdiği, ağrı algısını arttırdığı, ağrı inhibisyonunu bozduğu, KPAS ve depresyonu olan olgularda IL-10, sitokinler, oksidatif stres seviyelerinin arttığı, kortizolün yüksek olduğu ve bu durumun hücresel-hümoral immüniteyi negatif olarak etkilediği belirtilmektedir (75-78). $\mathrm{Bu}$ olgularda anksiyetenin karıncalanma ve hissizlik şeklinde yakınmalara neden olması sempatik sistemde anomali olduğunu göstermektedir. Psikojenik nedenler incelenirken katastrofik kişilik ya da düşünce yapısının önemli olduğunu vurgulamamız gerekmektedir. Buna göre saplantılı olarak adlandırılan ve "bu hastalık geçmeyecek", "tedavisi yok" gibi karamsar ve kötümser düşüncelere sahip kişilerde tedavinin son derece zor olduğu anlaşılmaktadır. Katastrofi ağrının supresyonunu engelleyerek etki edebilmektedir. Bu olgularda UPOINT ile ağrı skorları daha fazla olabilmektedir (79). Son dönemlerde pek çok hastalıkta olduğu gibi KPAS etiyolojisinde de genetik sebepler incelenmiştir (80-82). IL-10 AA genotipi ve fosfogliserat kinaz genotip gibi anomaliler saptanmıştır (83).

Üzerinde en çok çalışılan konulardan bir tanesi de KPAS ve soğuk ya da KPAS ve iklim arasındaki ilişkidir $(84,85)$. Özellikle Kanada ve Finlandiya gibi ülkelerde yapılan çalışmalarda bu konu açıklığa kavuşturulmaya çalışılmıştır. 2008-
2012 yılları arasında 77 olgunun incelendiği bir çalışmada olguların \%65'inin semptomlarının soğukla ilişkili olduğu gösterilmiştir (86). Yapılan çalışmalarda kış dönemlerinde ya da rüzgarlı ıslak havalarda yakınmaların 3 kata varan oranlarda arttığı, güneş 1şığ ile birlikte yakınmaların azaldığı bu olgularda aynı zamanda TNF- $\alpha$, IL-8 ve IL-10 seviyelerinin kontrol grubuna göre artmış olduğu saptanmıştır (87-89). Soğuk havanın alt üriner sistem semptomlarını arttırabileceği bildirilmiştir (90). Burada soğuğun vazokonstrüksiyon ve iskemiye yol açarak sinir iletim hızı ile kas kontraktil özelliklerini değiştirdiği bildirilmiştir. Lan ve ark.'larının 2009-2010 yılları arasında deniz seviyesine göre 400 metrede yaşayan 20-29 yaş grubunda 721, 30-39 yaş grubunda 900 ve 40-49 yaş grubunda ise 842 olmak üzere toplam 2463 olguyu benzer yaş gruplarında ve 3000 metrede yaşayan 2831 olgu ile karşılaştırdıkları çalışmalarında yüksek yerleşim yerlerinde yaşayanlarda KPAS semptomlarının daha fazla olduğu saptanmıştır (91). Bu çalışmada da; semptomlarla sitokin seviyeleri ve oksidatif stres arasında korelasyon olduğu belirtilmektedir. Kas kontraktilitesindeki değişikliğe bağlı olarak ejakülasyon ve işeme ile ilgili yakınmaların oluştuğu ileri sürülmüştür. Mesanede hücrelerdeki K+ geçirgenliğinin değişmesinin ağrı ile ilişkili olduğu, KPAS hastalarında da $\mathrm{K}+$ geçirgenliği olabileceği belirtilmektedir. $\mathrm{Bu}$ olgularda \%78-83 oranında saptanan pozitif $\mathrm{K}+$ sitrat testinin kadınlarda interstisyel sistittekine benzer oranlarda olduğu belirtilmiştir (92-94). Hastalıkta semptomların yiyeceklerle ilişkili olabileceği \%47.4 oranında alkol, acılı yemekler, çay ve kahve tüketimi ile ilişkili olduğu belirtilmektedir (95). Öte yandan, düşük eğitim seviyesi ve düşük gelir grubu ile genç yaşın semptom şiddeti ile korele olabileceği de bildirilmiştir (96).

Yukarıda sayılan faktörler içerisinde yer alan pelvik taban kaslarının fonksiyonları son derece önemlidir. Normal bir ejakülasyon, orgazm ve işeme için pelvik taban kaslarının normal ve koordineli çalışmasının son derece önemli olduğu bilinmektedir (97). Khorasani ve ark.'larının transabdominal USG ile yaptıkları çalışmada olduğu gibi KPAS'lı olgularda pelvik taban kasları mobilitesinin KPAS tanısı almayanlara göre daha az mobil olduğu bildirilmiştir (98). Benzer şekilde Davis ve ark.'ları da KPAS'lı olgulardaki ultrason ile yapılan incelemede saptanan anomalilerin ağrı, anksiyete ve cinsel işlev bozukluğu ile ilişkili olabileceğini belirtmiştir (64). Bununla ilişkili olarak, pelvik taban kasları terapisinin tedavi yaklaşımlarından biri olduğu görülmektedir (99). Bu olguların yakından incelenmesi sonrası Zermann ve ark.'larının belirttiği üzere, çoğunda patolojik hassasiyet ya da pelvik taban kaslarının fonksiyonlarında anomali saptanabilmektedir (100). Fiziksel aktiviteninde özellikle kanda inflamatuar belirteçler olan CRP seviyelerini düşürüp, antiinflamatuar etki ile KPAS olasılığını azaltabileceği yine fiziksel aktivitenin endojen endorfin, dopamin ve serotoninerjik sistem üzerine olan olumlu etkileri ile KPAS olasılığını azaltacağı bildirilmiştir (101). Anderson ve ark.'larının çalışmalarında ise KPAS olan olgularda adrenokortikotropik hormonlar (ACTH) \%30 daha düşük ve adrenal sensitivitenin daha fazla olduğu görülmüştür (102). Bir diğer çalışmada kortizol seviyesinin kontrol grubuna göre yüksek olduğu düşük ACTH seviyesi ya da strese düşük ACTH seviyesi ile yanıt verildiği saptanmıştır (103). Bir başka araştırmada ise; progesteronu kortikosteron ve 17 hidroksiprogeteronu 11-deoksikortizole dönüştüren CYP21A2 enzimin aktivitesinin düşük olduğu gösterilmiştir (104). 
Prostatitler, 1968 yılında Meares ve Stamey'in 4 tüp testini tanımlamalarından sonra sınıflandırılmışlardır (105). Dört tüp testinde 1. tüpe ilk 10 ml'lik idrar alınırken, $200 \mathrm{cc}$ idrar yapımı sonrası alınan 10 cc'lik idrar 2. tüpü, yaklaşık 1 dakika süren prostat masajı sonrası alınan prostat sekresyonu 3. tüpü ve en son alınan 10 cc'lik idrarda 4. tüpü oluşturmaktadır. Bu değerlendirmede 1. tüp üretra, 2. tüp mesane ve 3. ile 4. tüpte prostata karşılık gelmektedir Ürologlar tarafından rutin olarak 4 tüp testinin yapılmadığ 1 bildirilmektedir. Bir çalışmada Nickel ve ark.'ları hekimlerin \%70'inin 4 tüp testinin yararına inanmadıklarını ortaya koymuşlardır (106). Bu nedenlerden dolayı 1985 yılında Weidner ve Ebner tarafından 2 tüp testi ortaya atılmış ve bu test 1997 yılında Nickel tarafından popülarize edilmiştir (107).

Yukarıda da bahsedildiği üzere tanıda KPAS ile karışabilecek ek patolojilerin ayırt edilmesi gerekmektedir. Tanıda bu olgular ağrılı mesane sendromu ile karışabilirler. İşeme sonrası ağrının geçmesi ağrılı mesane sendromu için tipiktir. Bununla ilişkili şikayetlerin süresi, idrarda kanama olup olmadığı, taş düşürme öyküsü, yan ağrısı, yakın zamanda geçirilmiş aktif üriner enfeksiyon, geçirilmiş pelvik ve üriner sistem cerrahileri sorgulanmalıdır. Buna ilave olarak multipl skleroz, diabetes mellitus gibi sistemik ve metabolik hastalıklar ya da; kronik ilaç kullanımı öyküsü araştırılmalıdır. Parmakla rektal muayenede prostat büyüklüğü ve rektal bölge patolojileri ortaya konulacaktır. Fizik muayenede testosteron yetmezliğini düşündürecek bulgular, testis atrofisi, lokal üriner patolojiler ve elbetteki bu hastalıkta sözkonusu olan myofasial ağrılı noktalar tespit edilmelidir. Klinik deneyim olarak bu olgularda inguinal kanal, femoral bölge ya da pubik alanlarda palpasyonla ağrılı alanların tespit edildiğini söyleyebiliriz. Laboratuar incelemesi olarak tam idrar tekiki ve idrar kültürü, aktif üriner infeksiyonu ortaya koymak için gerekmektedir. Özetle öykü, parmakla rektal muayene, fizik muayene, tam idrar tetkiki ve idrar kültürü her hastaya kesinlikle yapılmalıdır. Tanı değerini arttırmak ve tedaviyi takip etmek ve ilave patolojileri ayırtetmek için dört tüp testi, toplam 9 sorudan oluşan KPAS semptom skoru, idrar akım hızı ve postmiksiyonel rezidü, sitoloji yapılması ise önerilmektedir. Semptom skoru hastalığın şiddeti ile tedaviye yanıtın nispeten objektif bir göstergesi olarak faydalı olmaktadır. İdrar akım hızı olası bir darlık ya da BPH'ı öngörmede önemlidir. Yukarıda da bahsedildiği üzere, etkin bir tedavi planı için UPOINTs sistemi kullanılarak semptomlar sinıflandırılmalıdır. Bunların haricinde nörolojik şüphe durumunda ya da başlangıç tedavilerine yanıt yoksa ürodinami, TRUS, üriner sistem ultrasonografisi, bilgisayarlı tomografi, manyetik rezonans inceleme, serum PSA düzeyi, sistoskopi ve semen analizi gibi tetkikler isteğe bağlı olarak yapılabilir. Tanıda moleküler olarak tip 3A ve 3B ayırımı yapmak için prostatik sıvıda nitrik oksit (NO) bakılacağı bunun 3A'da daha yüksek olduğu bildirilmiştir (91). Nirik oksit'in düşük konsantrasyonlarının aksine yüksek konsantrasyonlarda sitotoksik olduğu ve inflamasyonm göstergesi olduğu bilinmektedir. Tanıda her ne kadar seminal plazmada IL-8 bakılmasının önemli olduğu belirtilse de klinik pratikte rutin olarak yapılan incelemeler değildir (108). Benzer şekilde IL-6, CCL3, CCL4, CCL17, CCL22, 16s rRNA, Semende IL- $\beta 1 b$, $Z n$ ve TNF- $\alpha$ gibi yapıların da bu olgularda seminal plazmada arttığ gösterilse de rutin pratikte bakılmamaktadırlar $(109,110)$.

\section{Kaynaklar}

1. Erdemir F, Parlaktaş BS, Uluocak N. "Prostatitlerin Patofizyolojisi, Tanısı, TedavisiveDeğerlendirilmesindeki Yenilikler. Üroloji Bülteni. 2007;18(4):147-155.

2. Forrest JB, Nickel JC, Moldwin RM. Chronic prostatitis/ chronic pelvic pain syndrome and male interstitial cystitis: enigmas and opportunities. Urology. 2007;69(4 Suppl):60-3.

3. McNaughton Collins M, Pontari MA, O'Leary MP, Calhoun EA, Santanna J, Landis JR, et al. Quality of life is impaired in men with chronic prostatitis: The Chronic Prostatitis Collaborative Research Network. J Gen Intern Med. 2001;16:656-62.

4. Krieger JN, Nyberg L, Jr, Nickel JC. NIH consensus definition and classification of prostatitis. JAMA. 1999;282:236-7.

5. Cheah PY, Liong HL, Yuen KH, Teh CL, Khor T, Yang JR, Yap HW, Krieger JN. Chronic prostatitis: symptom survey with follow-up clinical evaluation. Urology. 2003;61:60-64.

6. Roberts RO, Lieber MM, Rhodes T, Girman CJ, Bostwick DG, Jacobsen SJ. Prevalence of a physician-assigned diagnosis of prostatitis: the Olmsted County Study of Urinary Symptoms nd Health Status Among Men. Urology. 1998;51:578-584

7. Suskind AM, Berry SH, Ewing BA, Elliott MN, Suttorp MJ, Clemens JQ. The prevalence and overlap of interstitial cystitis/bladder pain syndrome andchronic prostatitis/ chronic pelvic pain syndrome in men: results of the RAND Interstitial Cystitis Epidemiology male study. J Urol. 2013;189(1):141-5.

8. Konkle KS, Clemens JQ. New paradigms in understanding chronic pelvic pain syndrome. Curr Urol Rep. 2011;12(4):278-83.

9. Mehik A, Hellström P, Lukkarinen O, Sarpola A, Järvelin M. Epidemiology of prostatitis in Finnish men: a population-based cross-sectional study. BJU Int 2000;86:443-8.

10. Nickel JC, Downey J, Hunter D, Clark J. Prevalence of prostatitis-like symptoms in a population based study using the National Institutes of Health Chronic Prostatitis Symptom Index. J Urol. 2001;165:842-845.

11. Kunishima Y, Matsukawa M, Takahashi S. National Institutes of Health Chronic Prostatitis Symptom Index for Japanese men. Urology. 2002;60:74-77.

12. Tan JK, Png DJ, Liew LC, Li MK, Wong ML. Prevalence of prostatitis-like symptoms in Singapore: a populationbased study. Singapore Med J. 2002; 43:189-193.

13. Wallner LP, Clemens JQ, Sarma AV. Prevalence of and risk factors for prostatitis in African American men: the Flint Men's Health study. Prostate. 2009;69(1):24-32.

14. Krieger JN, Riley DE, Cheah PY, Liong ML, Yuen KH. Epidemiology of prostatitis: new evidence for a worldwide problem. World J Urol. 2003 Jun;21(2):70-4.

15. Wagenlehner FME, Till JW. National Institutes of Health Chronic Prostatitis Symptom Index (NIH-CPSI) Symptom Evaluation in Multinational Cohorts of Patients with Chronic Prostatitis/Chronic Pelvic Pain Syndrome. Eur Urol. 2013;63:953-9.

16. Muller A, Mulhall JP. Sexual dysfunction in the patient with prostatitis. Curr Opin Urol. 2005;15:404-9. 
17. Anderson RU, Wise D, Sawyer T, Chan CA. Sexual dysfunction in men with chronic prostatitis/chronic pelvic pain syndrome: improvement after trigger point release and paradoxical relaxation training. J Urol. 2006;176:1534-8.

18. Liang C, Zhang X, Hao Z, Shi H, Wang K. Investigation and analysis of chronic prostatitis and sexual dysfunction. Zhonghua Nan Ke Xue. 2004;10:434-6.

19. Biri H, Tunc L. Erektil Disfonksiyon icin risk faktorleri. Erkek ve kadın cinsel sağlığı. İstanbul, 2004;125-33.

20. Shamloul R, el-Nashaar A. Chronic prostatitis in premature ejaculation: a cohort study in 153 men. J Sex Med. 2006;3:150-4.

21. Xing JP, Fan JH, Wang MZ, Chen XF, Yang ZS. Survey of the prevalence of chronic prostatitis in men with premature ejaculation. Zhonghua Nan Ke Xue. 2003;9:451-3.

22. Uluocak N, Erdemir F, Cumurcu BE, Celikel FC, Parlaktaş BS. Erkeklerde antidepresan ilac kullanımının orgazm ve ejakulasyona olan etkileri. Klinik Psikofarmakoloji Bulteni. 2006;16:104-8.

23. Carson C, Gunn K. Premature ejaculation: definition and prevalence. Int J Impot Res. 2006;18:5-13.

24. $\mathrm{Ku} \mathrm{JH}, \mathrm{Kim}$ SW, Paick JS. Epidemiologic risk factors for chronic prostatitis. Int J Androl. 2005;28:317-27.

25. Nickel JC, Shoskes D. Phenotypic approach to the management of chronic prostatitis/chronic pelvic pain syndrome. Curr Urol Rep. 2009;10:307-12.

26. Shoskes DA, Nickel JC, Dolinga R. Clinical phenotyping of patients with chronic prostatitis/chronic pelvic pain syndrome and correlation with symptom severity. Urology. 2009;73:538-42.

27. Shoskes DA, Nickel JC, Rackley RR. Clinical phenotyping in chronic prostatitis/chronic pelvic pain syndrome and interstitial cystitis: a management strategy for urologic chronic pelvic painsyndromes. Prostate Cancer Prostatic Dis. 2009;12:177-83.

28. Nickel JC, Shoskes D, Irvine-Bird K. Clinical phenotyping of womenwith interstitial cystitis/painful bladder syndrome: a key to classificationand potentially improved management. J Urol. 2009;182:155-60.

29. Shoskes DA, Nickel JC, Dolinga R, et al. Clinical phenotyping ofpatients with chronic prostatitis/chronic pelvic pain syndrome andcorrelation with symptom severity. Urology. 2009;73:538-42.

30. Silverberg M. California state journal of medicine. 1916;14(2):60-4.

31. Park H, Sim SM, Lee G. The presence of Chlamydia is associated with increased leukocyte counts and pain severity in men with chronic pelvic pain syndrome. Urology. 2015;85(3):574-9.

32. Karataş OF. The presence of Chlamydia is associated with increased leukocyte counts and painseverity in men with chronic pelvic pain syndrome. Urology. 2015;85(3):574-9.

33. Nickel JC, Alexander RB, Schaeffer AJ, Landis JR, Knauss JS, Propert KJ. ChronicProstatitis Collaborative Research Network Study Group. Leukocytes and bacteria in men with chronic prostatitis/chronic pelvic painsyndrome compared to asymptomatic controls. J Urol. 2003;170(3):818-22.
34. Xiao J, Ren L, Lv H, Ding Q, Lou S, Zhang W, Dong Z. Atypical microorganisms in expressed prostatic secretion from patients with chronicprostatitis/chronic pelvic pain syndrome: microbiological results from a case-control study. Urol Int. 2013;91(4):410-6.

35. Skerk V, Cajić V, Markovinović L, Roglić S, Zekan S, Skerk $\mathrm{V}$, Radosević V, Tambić Andragević A. Etiology of chronic prostatitis syndrome in patients treated at the university hospital for infectious diseases "Dr. Fran Mihaljević" from 2003 to 2005. Coll Antropol. 2006;30 Suppl 2:145-9.

36. Pontari MA. Etiology of chronic prostatitis/chronic pelvic pain syndrome: psychoimmunoneurendocrine dysfunction (PINE syndrome) or just a really bad infection. World J Urol. 2013;31:725-32.

37. Krieger JN, Riley DE, Roberts MC, Berger RE. Diverse and related $16 \mathrm{~S}$ rRNA-encoding DNA sequences in prostate tissues of men with chronic prostatitis. J Clin Microbiol. 1998;36(6):1646-52.

38. Tanner MA, Shoskes D, Shahed A, Pace NR. Prevalence of corynebacterial $16 \mathrm{~S}$ rRNA sequences in patients with bacterial and "nonbacterial" prostatitis. J Clin Microbiol. 1999;37(6):1863-70.

39. Shoskes DA, Shahed AR. Detection of bacterial signal by $16 \mathrm{~S}$ rRNA polymerase chain reaction in expressed prostatic secretions predicts response to antibiotic therapy in men with chronicpelvic pain syndrome. Tech Urol. 2000;6(3):240-2.

40. Le B, Schaeffer AJ. Chronic prostatitis. BMJ Clin Evid. 2011 Jul 4;2011. pii: 1802.

41. Chapple CR, Blease SC, Rickards D. What is the clinical significance of urethroprostatic reflux as a radiological finding during videocystourethrography in neurologically normal patients? Eur Urol. 1990;17:296-8.

42. Turner PJ, Eardley I, Fowler RC. The use of transrectal ultrasonography in the diagnosis of urethroprostatic reflux. BJUI. 1996;77:314-5.

43. Zu XB, Ye ZQ, Zhou SW, Qi L, Yang ZQ. Chronic prostatitis with non-neurogenic detrusor sphincter dyssynergia: diagnosis and treatment. Zhonghua Nan Ke Xue. 2010;16(2):146-9.

44. Evans DTP, Jaleel H, Keefe A. Retrospective review of clinical practice in chronic pelvic pain syndrome i.e. category III chronic prostatitis at two hospital sites over five years 2000-2005 (an audit). Int J STD and AIDS. 2007;18:276-80.

45. Motrich RD, Breser ML, Sánchez LR, Godoy GJ, Prinz I, Rivero VE. IL-17 is not essential for inflammation and chronic pelvic pain development in an experimental model of chronic prostatitis/chronic pelvic pain syndrome. Pain. 2016;157(3):585-97.

46. Bicer F, Altuntas CZ, Izgi K, Ozer A, Kavran M, Tuohy VK, Daneshgari F. Chronic pelvic allodynia is mediated by CCL2 through mast cells in an experimental autoimmune cystitis model. Am J Physiol Renal Physiol. 2015;308(2):103-13.

47. Quick ML, Wong L, Mukherjee S, Done JD, Schaeffer AJ, Thumbikat P. Th1-Th17 cells contribute to the development of uropathogenic Escherichia coli-induced chronic pelvic pain. PLoS One. 2013;8(4):e60987. doi: 10.1371/journal.pone.0060987.

48. Iczkowski KA. Chronic pelvic pain syndrome: a role for aberrant cytokine function. J Urol. 2010;184(4):1253-4. 
49. Yuan Z, Liu X, Deng W, Lai X, Yan Z, Zheng R. Correlation study of chronic nonbacterial prostatitis with the levels of COX-2 and PGE2 in prostatic secretion. Int Urol Nephrol. 2014;46(10):1871-5.

50. Watanabe $\mathrm{T}$, Inoue $\mathrm{M}$, Sasaki $\mathrm{K}$, Araki M, Uehara S, Monden K, Saika T, Nasu Y, Kumon H, Chancellor MB. Nerve growth factor level in the prostatic fluid of patients with chronicprostatitis/chronic pelvic pain syndrome is correlated with symptom severity and response to treatment. BJU Int. 2011;108(2):248-51.

51. Pontari MA, Ruggieri MR. Mechanisms in prostatitis/ chronic pelvic pain syndrome. J Urol. 2004;172(3):839-45.

52. Miller LJ, Fischer KA, Goralnick SJ, Litt M, Burleson JA, Albertsen P, Kreutzer DL. Nerve growth factor and chronic prostatitis/chronic pelvic pain syndrome. Urology. 2002;59(4):603-8.

53. Lewin GR. Trends Neurosci. Pain. 1995: Petty BG. Ann Neurol.

54. Özkorkmaz EG. Mast hücresi. AKÜ Fen Bilimleri Dergisi. 2008;2:87-101.

55. Chen Y, Song B, Jin XY, Xiong EQ, Zhang JH. Possible mechanism of referred pain in the perineum and pelvis associated with the prostate in rats. J Urol. 2005;174(6):2405-8.

56. Korkmaz S, Karadağ MA, Hamamcioğlu K, Sofikerim M, Aksu M. Electrophysiological identification of central sensitization in patients with chronic prostatitis. Miscellaneus. 2015;12:2280-4.

57. Wong L, Done JD, Schaeffer AJ, Thumbikat P. Experimental autoimmune prostatitis induces microglial activation in the spinal cord. Prostate. 2015 Jan;75(1):509.

58. Roman K, Done JD1, Schaeffer AJ, Murphy SF, Thumbikat P. Tryptase-PAR2 axis in experimental autoimmune prostatitis, a model for chronic pelvic pain syndrome. Pain. 2014;155(7):1328-38.

59. Wilson MJ, Woodson M, Wiehr C, Reddy A, Sinha AA. Matrix metalloproteinases in the pathogenesis of estradiol-induced nonbacterial prostatitis in the lateral prostate lobe of the Wistar rat. Exp and Mol Pathology. 2004;77(1):7-17.

60. Woodworth D, Mayer E, Leu K, Ashe-McNalley C, Naliboff BD, Labus JS, Tillisch K, Kutch JJ, Farmer MA, Apkarian AV, Johnson KA, Mackey SC, Ness TJ, Landis JR, Deutsch G, Harris RE, Clauw DJ, Mullins C, Ellingson BM. MAPP Research Network. Unique Microstructural Changes in the Brain Associated with Urological ChronicPelvic Pain Syndrome (UCPPS) Revealed by Diffusion Tensor MRI, Super-Resolution Track Density Imaging, and Statistical Parameter Mapping: A MAPPNetwork Neuroimaging Study. PLoS One. 2015 Oct 13;10(10):e0140250. doi: 10.1371/journal. pone.0140250. eCollection 2015.

61. Kim DS, Jeong TY, Kim YK, Chang WH, Yoon JG, Lee SC. Usefulness of a myofascial trigger point injection for groin pain in patients withchronic prostatitis/chronic pelvic pain syndrome: a pilot study. Arch Phys Med Rehabil. 2013;94(5):930-6.

62. Anderson RU, Sawyer T, Wise D, Morey A, Nathanson $\mathrm{BH}$. Painful myofascial trigger points and pain sites in men with chronicprostatitis/chronic pelvic pain syndrome. J Urol. 2009;182(6):2753-8.
63. Anderson RU, Harvey RH, Wise D, Nevin Smith J, Nathanson $\mathrm{BH}$, Sawyer T. Chronic pelvic pain syndrome: reduction of medication use after pelvic floorphysical therapy with an internal myofascial trigger point wand. Appl Psychophysiol Biofeedback. 2015;40(1):45-52.

64. Davis SN, Morin M, Binik YM, Khalife S, Carrier S. Use of pelvic floor ultrasound to assess pelvic floor muscle function in Urological Chronic Pelvic Pain Syndrome in men. J Sex Med. 2011;8(11):3173-80.

65. Hetrick DC, Glazer H, Liu YW, Turner JA, Frest M, Berger RE. Pelvic floor electromyography in men with chronic pelvic pain syndrome: a case-control study. Neurourol Urodyn. 2006;25(1):46-9.

66. Liu Y, Mo JQ, Hu Q, Boivin G, Levin L, Lu S, Yang D, Dong Z, Lu S. Targeted overexpression of vav3 oncogene in prostatic epithelium induces nonbacterialprostatitis and prostate cancer. Cancer Res. 2008;68(15):6396-406.

67. Goodarzi D, Cyrus A, Baghinia MR, Kazemifar AM, Shirincar M. The efficacy of zinc for treatment of chronic prostatitis. Acta Med Indones. 2013;45(4):259-64.

68. Cui D, Han G, Shang Y, Mu L, Long Q, Du Y. The effect of chronic prostatitis on zinc concentration of prostatic fluid and seminal plasma: a systematic review and metaanalysis. Curr Med Res Opin. 2015;31(9):1763-9.

69. Lombardo F, Fiducia M, Lunghi R, Marchetti L, Palumbo A, Rizzo F, Koverech A, Lenzi A, Gandini L. Effects of a dietary supplement on chronic pelvic pain syndrome (Category IIIA), leucocytospermia and semen parameters. Andrologia. 2012 May;44 Suppl 1:672-8.

70. Zhao $\mathrm{H}$, Shen JH, Chen YP, Yu ZY, Dong Q, Li H. Changes of seminal parameters, zinc concentration and antibacterial activity in patients with non-inflammatory chronic prostatitis/chronic pelvic pain syndrome. Zhonghua Nan Ke Xue. 2008;14(6):530-2.

71. Zhang R, Sutcliffe S, Giovannucci E, Willett WC, Platz EA, Rosner BA, Dimitrakoff JD, Wu K. Lifestyle and Risk of Chronic Prostatitis/Chronic Pelvic Pain Syndrome in a Cohort of United States Male Health Professionals. J Urol. 2015;194(5):1295-300.

72. Park JH, Cho IC, Kim YS, Kim SK, Min SK, Kye SS. Body mass index, waist-to-hip ratio, and metabolic syndrome as predictors of middle-aged men's health. Korean J Urol. 2015 May;56(5):386-92.

73. Nickel JC, Berger R, Pontari M. Changing paradigms for chronic pelvic pain: a report from the chronic pelvic pain/chronic prostatitis scientific workshop, october 19-21, 2005, Baltimore, MD. Rev Urol. 2006 Winter;8(1):28-35.

74. White HD, Robinson TD. A novel use for testosterone to treat central sensitization of chronic pain in fibromyalgia patients. Int Immunopharmacol. 2015;27(2):244-8.

75. Ahn SG, Kim SH, Chung KI, Park KS, Cho SY, Kim HW. Depression, anxiety, stress perception, and coping strategies in korean military patients with chronic prostatitis/chronic pelvic pain syndrome. Korean J Urol. 2012;53(9):643-8.

76. Chung SD, Lin HC. Association between chronic prostatitis/chronic pelvic pain syndrome andanxiety disorder: a population-based study. PLoS One. 2013 May 15;8(5):e64630. doi: 10.1371/journal.pone.0064630. Print 2013. 
77. Ahn SG, Kim SH, Chung KI, Park KS, Cho SY, Kim HW. Depression, anxiety, stress perception, and coping strategies in korean military patients with chronic prostatitis/chronic pelvic pain syndrome. Korean J Urol. 2012;53(9):643-8.

78. Zhang GX, Bai WJ, Xu T, Wang XF. A preliminary evaluation of the psychometric profiles in Chinese men with chronicprostatitis/chronic pelvic pain syndrome. Chin Med J (Engl). 2011;124(4):514-8.

79. Hedelin $\mathrm{H}$, Johannisson $\mathrm{H}$, Welin L. Prevalence of the chronic prostatitis/chronic pelvic pain syndrome among 40-69-year-old men residing in a temperate climate. Scand J Urol. 2013 Oct;47(5):390-2.

80. Shoskes DA, Albakri Q, Thomas K, Cook D. Cytokine polymorphisms in men with chronic prostatitis/chronic pelvic painsyndrome: association with diagnosis and treatment response. J Urol. 2002;168(1):331-5.

81. Arisan ED, Arisan S, Kiremit MC, Tiğli H, Caşkurlu T, Palavan-Unsal N, Ergenekon E. Manganese superoxide dismutase polymorphism in chronic pelvic painsyndrome patients. Prostate Cancer Prostatic Dis. 2006;9(4):426-31.

82. Dimitrakov J, Guthrie D. Genetics and phenotyping of urological chronic pelvic pain syndrome. J Urol. 2009 Apr;181(4):1550-7.

83. Riley DE, Krieger JN. X Chromosomal short tandem repeat polymorphisms near the phosphoglycerate kinase gene in men with chronic prostatitis. Biochim Biophys Acta. 2002;1586(1):99-107.

84. Hedelin H, Jonsson K. Chronic abacterial prostatitis and cold exposure: an explorative study. Scand J Urol Nephrol. 2007;41(5):430-5.

85. $\mathrm{Ku} \mathrm{JH}$, Kim ME, Lee NK, Park YH. Influence of environmental factors on chronic prostatitis-like symptoms in young men: results of a community-based survey. Urology. 2001;58(6):853-8.

86. Shin JH, Lee G. Seasonal changes in symptoms in patients with chronic prostatitis/chronic pelvic pain syndrome: a seasonal follow-up study. Scand J Urol. 2014;48(6):533-7.

87. Hedelin H, Jonsson K. Chronic prostatitis/chronic pelvic pain syndrome: symptoms are aggravated bycold and become less distressing with age and time. Scand J Urol Nephrol. 2007;41(6):516-20.

88. Hedelin H, Jonsson K, Lundh D. Pain associated with the chronic pelvic pain syndrome is strongly related to the ambient temparature. Scand J Urol Nephrol. 2012;46(4):279-83.

89. Hedelin H, Johannisson $H$, Welin L. Prevalence of the chronic prostatitis/chronic pelvic pain syndrome among 40-69-year-old men residing in a temperate climate. Scand J Urol. 2013;47(5):390-2.

90. Watanabe T, Maruyama S, Kageyama S, Shinbo H, Otsuka A. Seasonal changes in symptom score and uroflowmetry in patients with lower urinary tract symptoms. Scand J Urol Nephrol. 2007;41:521-6.

91. Lan T, Wang Y, Chen Y, Qin W, Zhang J, Wang $Z$, Zhang $W$, Zhang $X$, Yuan J, Wang $H$. Influence of environmental factors on prevalence, symptoms, and pathologic process of chronic prostatitis/chronic pelvic pain syndrome in northwest China. Urology. 2011;78(5):1142-9.
92. Hosseini A, Herulf M, Ehrén I. Measurement of nitric oxide may differentiate between inflammatory and non-inflammatory prostatitis. Scand J Urol Nephrol. 2006;40(2):125-30.

93. Parsons CL, Albo M. Intravesical potassium sensitivity in patients with prostatitis.J Urol. 2002;168:1054-7.

94. Parsons CL, Rosenberg MT, Sassani P, Ebrahimi K, Koziol JA, Zupkas P. Quantifying symptoms in men with interstitial cystitis/prostatitis, and its correlation with potassium-sensitivity testing. BJU Int. 2005;95(1):8690.

95. Herati AS, Shorter B, Srinivasan AK, Tai J, Seideman C, Lesser M, Moldwin RM. Effects of foods and beverages on the symptoms of chronic prostatitis/chronic pelvic pain syndrome. Urology. 2013;82:1376-80.

96. Schaeffer AJ, Landis JR, Knauss JS, Propert KJ, Alexander RB, Litwin MS, Nickel JC, O'Leary MP, Nadler RB, Pontari MA, Shoskes DA, Zeitlin SI, Fowler JE Jr, Mazurick CA, Kishel L, Kusek JW, Nyberg LM; Chronic Prostatitis Collaborative Research Network Group. Demographic and clinical characteristics of men with chronic prostatitis: the national institutes of health chronic prostatitis cohort study. J Urol. 2002;168:593-8.

97. Westesson KE, Shoskes DA. Chronic prostatitis/chronic pelvic pain syndrome and pelvic floor spasm: can we diagnose and treat? Curr Urol Rep. 2010;11(4):261-4.

98. Khorasani B, Arab AM, Sedighi Gilani MA, Samadi V, Assadi H. Transabdominal ultrasound measurement of pelvic floor muscle mobility in men with and without chronic prostatitis/chronic pelvic pain syndrome. Urology. 2012;80(3):673-7.

99. Cornel EB, van Haarst EP, Schaarsberg RW, Geels J. The effect of biofeedback physical therapy in men with Chronic Pelvic Pain Syndrome Type III. Eur Urol. 2005;47(5):607-11.

100.Zermann DH, Ishigooka M, Doggweiler R, Schmidt RA. Neurourological insights into the etiology of genitourinary pain in men. J Urol. 1999;161(3):903-8.

101. Rethorst CD, Wipfli BM, Landers DM. The antidepressive effects of exercise: a meta-analysis of randomized trials. Sports Med. 2009;39(6):491-511.

102. Anderson RU, Orenberg EK, Morey A, Chavez N, Chan CA. Stress induced hypothalamus-pituitary-adrenal axis responses and disturbances in psychological profiles in men with chronic prostatitis/chronic pelvic pain syndrome. J Urol. 2009;182(5):2319-24.

103. Anderson RU, Orenberg EK, Chan CA, Morey A, Flores V. Psychometric profiles and hypothalamic-pituitaryadrenal axis function in men with chronic prostatitis/ chronic pelvic pain syndrome. J Urol. 2008;179(3):95660.

104. Dimitrakov J, Joffe HV, Soldin SJ, Bolus R, Buffington CA, Nickel JC. Adrenocortical hormone abnormalities in men with chronic prostatitis/chronic pelvic pain syndrome.; Urology. 2008;71(2):261-6.

105. Meares EM, Stamey TA. The Bacteriologic localization patterns in bacterial prostatitis and urethritis. Invest Urol, 5: 492, 1968.

106. Nickel JC, Nigro M, Valiquette L, Anderson P, Patrick A, Mahoney J, Buckley R, Corcos J, Hosking D. Diagnosis and treatment of prostatitis in Canada. Urology. 1998;52:797-802. 
107. Nickel JC. Classification and diagnosis of prostatitis: a gold standard? Andrologia, 35: 160, 2003.

108. Penna G, Mondaini N, Amuchastegui S, Degli Innocenti S, Carini M, Giubilei G, Fibbi B, Colli E, Maggi M, Adorini L. Seminal plasma cytokines and chemokines in prostate inflammation: interleukin 8 as a predictive biomarker in chronic prostatitis/chronic pelvic pain syndrome and benign prostatic hyperplasia. Eur Urol. 2007;524-33.

109. Pontari MA, Ruggieri MR. Mechanisms in prostatitis/ chronic pelvic pain syndrome. J Urol. 2004;172(3):839-45.
110. Kramer G, Marberger M. Could inflammation be a key component in the progression of benign prostatic hyperplasia? Curr Opin Urol. 2006;16(1):25-9.

Yazışma Adresi:

Fikret Erdemir,

Gaziosmanpaşa Üniversitesi, Tıp Fakültesi, Üroloji Anabilim Dalı, Tokat

Tel: +905056971052

e-mail: fikreterdemir@mynet.com 